\title{
Non-Destructive Classification of Thai Cha-Nee Durian Maturity With Near-Field Reflection Mode Measurement Using a 3.4-GHz Microwave Sensor
}

\author{
Pakornkiat Sawetmethikul* \\ Department of Industrial Education \\ Rajamangala University of Technology Thanyaburi \\ Pathumthani, Thailand \\ *pkkt@rmutt.ac.th
}

\author{
Kittiwan Nimkerdphol \\ Department of Computer Engineering \\ Rajamangala University of Technology Thanyaburi \\ Pathumthani, Thailand \\ kittiwan_n@en.rmutt.ac.th
}

\begin{abstract}
This paper proposes an investigation of Thai ChaNee durian maturity with reflection mode measurement using a simple microwave sensor based planar structure. The microwave sensor was a "Pencil-like shaped probe", which were made of a FR4 laminate; dielectric constant $\left(\varepsilon_{\mathrm{r}}\right)=4.4$, dissipation factor $(\tan \delta)=0.018$, substrate thickness $(h)=1.6 \mathrm{~mm}$, and copper thickness $(t)=0.035 \mathrm{~mm}$. The resonant frequency was designed at $3.4 \mathrm{GHz}$ to avoid interferences from wireless communication channels. The distance between sensor and durian was recommended at less than $10 \mathrm{~mm}$, due to near-field region. Referring to experimental results, durian maturity was predicted by reflection coefficient $|\Gamma| ;|\Gamma|_{\text {immature }} \geq 0.53,0.28 \leq|\Gamma|_{\text {semi- }}$ mature $\leq \mathbf{0 . 4 3},|\Gamma|_{\text {mature }} \leq \mathbf{0 . 1 9}$, which achieved prediction accuracy at $91.55-99.0 \%$.
\end{abstract}

Keywords-durian maturity, microwave sensor, fruit maturity measurement, reflection mode measurment

\section{INTRODUCTION}

"Thai Durian" is an important agricultural product of Thai fruits that has made a high income at 51.181 Trillion Baht per year (for fresh, frozen, preserved, and freeze dried durians) in the last year, especially $88.86 \%$ of income obtained by fresh durian at 45.481 Trillion Baht [1]. Meanwhile, there were a large percentage of immature durians exported, which was a serious problem caused of underpricing. In the beginning of 2014, Thai Agricultural Standard: TAS 3-2013 was therefore announced by National Bureau of Agricultural Commodity and Food Standards, which was a reference standard with regards to classes, weight, shapes, packaging, and maturity properties [2]. However, it may need an accurate instrument to avoid human error from maturity classification.

Referring to literatures surveyed [3-10], there are several measurement techniques for durian maturity evaluation, such as electrical impedance and dielectric properties, vibration and ultrasonic, microwave near/far fields and reflection coefficient, and visible light absorbance measurements. In early works, dielectric properties determination of agricultural products was proposed by using a low frequency range at $1-50 \mathrm{MHz}[3,4]$.
Electrical impedance spectroscopy was investigated to model the dry matter content of durian using partial least squares regression, where impedance measurement was taken on the stem and the rind of durian samples at various stage of maturity based on the number of days after anthesis. The impedance parameter at frequencies of 1,41 and $200 \mathrm{kHz}$ were employed to model the dry matter content of pulp, which were used to evaluate immature and mature classes with less accuracy of $83.3 \%$ [5]. The optimized vibration and ultrasonic were studied to measure durian maturity which were transferred in the area between prickles located at the middle of durian. The signal source was a laser doppler used to extract high frequency by wavelet transform and converted into spectrum form, where template matching was performed by correlation between high frequency spectrum and templates in order to determine durian maturity. The experimental results by using force vibration and ultrasonic achieved accuracy around 95\% [6]. Stem strength and resonant frequency technique was used to measure durian maturity with 7 stages of maturity starting from 105 days to 136 days after blossom. The stem strength was measured by a uniquely built device and force-deformation responses to radial compression, while resonant frequency was measured by sound of tapping. Afterward, pulp of sample was oven dried for determination of dry mater percentage which was used as maturity reference. The linear model was later made to predict maturity of durian with correlation coefficient [7]. Later works, radio frequency $(\mathrm{RF})$ and microwave bands were also studied. The 915-MHz wireless sensor was applied to classify durian maturity by adopting the principle of wireless communication channel based Rician k-factors. The immature durian offered higher reflected wave-based k-factors but lower scattered wave-based k-factors. The results showed prediction accuracy at $92.7 \%$ [8]. The microwave free space at 2-3 GHz band with transmission mode measurement was studied by using insertion loss measurement to estimate complex permittivity. The results were compared with percentage of dry-weight as an standard durian maturity determination. The proposed system offered fast determination with $90 \%$ of accuracy [9]. Moreover, visible spectroscopy of the spine of durian was investigated to classify 
maturity by model of absorbance spectra transformed by the standard normal variate. The durian samples studied were a range of 113 to 134 days after anthesis. The classification was attributable to the absorbance of chlorophyll, carotenoids, and anthocyanins the in spine of 'Monthong' durian what achieved the best accuracy of classification at $94.7 \%$ [10]. Moreover, microwave sensing was applied as our studies, such as reinforced concrete inspection, and paddy moisture measurement $[11,12]$.

In this paper, we studied non-destructive classification of Che-Nee durian maturity; immature, semi-mature and mature classes by means of return loss (S11) measurement with nearfield reflection mode, where microwave probe was made of a FR4 laminate having dielectric constant $(\varepsilon r)=4.4$, dissipation factor $(\tan \delta)=0.018$, substrate thickness $(\mathrm{h})=1.6 \mathrm{~mm}$, and copper thickness $(\mathrm{t})=0.035 \mathrm{~mm}$. The resonant frequency was designed at $3.4 \mathrm{GHz}$ to avoid interferences from other wireless communication channels. The details of measurement system, microwave sensor, and experimental results are described in the subsequent sections.

\section{THEORY OF MEASUREMENT SYSTEM}

\section{A. Near-Field vs. Far-Field Regions}

The radiation of antenna can be measured either near-field or far-field ranges depending on applications. In general, farfield measurement is considered to antennas used in wireless communications, which referred to the distance from source at more than $2 \mathrm{D}^{2} / \lambda$, where $\mathrm{D}$ is the largest dimension of antenna (D should be large compared to $\lambda$ ), and near-field range include reactive and radiating (Fresnel region) is preferred to a specific application, such as microwave imaging [13-15]; for very short dipole or equivalent radiator, the outer boundary is taken to exist at a distance of $\lambda / 2 \pi$. If the antenna has a maximum overall dimension which is very small compared to $\lambda$, the radiating near-field region may not exist. Thus, the inner boundary is taken to be the distance $R \geq 0.62\left(D^{3} / \lambda\right)^{0.5}$ and the outer boundary distance $\mathrm{R}<2 \mathrm{D}^{2} / \lambda$. Fig. 1 shows near-field and far-field with field distribution as various regions $[16,17]$.

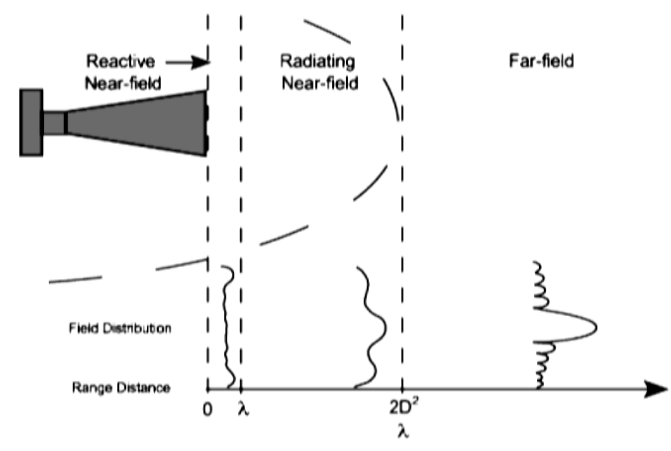

Fig. 1. Typical changes of field distribution from reactive near-field toward the far-field regions; reactive near-field $(0-$ to- $\lambda)$, radiating near-field $(\lambda$-to$\left.2 \mathrm{D}^{2} / \lambda\right)$, and far-field $\left(>2 \mathrm{D}^{2} / \lambda\right)$ regions [17].

\section{B. Transmission and Reflection Mode Measurements}

In general, schematic of microwave measurement includes transmission and reflection mode measurements [15], as shown in Fig. 2. The transmission mode measurement requires two probes for transmission and reflection to sense transmittance or insertion loss $\left(S_{21}\right)$, while reflection mode measurement needs single probe for transmission and reflection to sense reflectance or return loss $\left(\mathrm{S}_{11}\right)$. In practice, it depends on sample properties to decide measurement mode, especially near-field microwave sensing prefers reflection mode measurement as published in [11,12,18-22], where transmitted and reflected waves based near-field region (non-radiative and radiative) are shown in Fig. 3. In the figure, electric and magnetic fields in the nonradiative (reactive) range may be difficult to measure, while radiative range (Fresnel) is far enough to measure that refers to the distance between probe and sample as seen in Fig. 2.
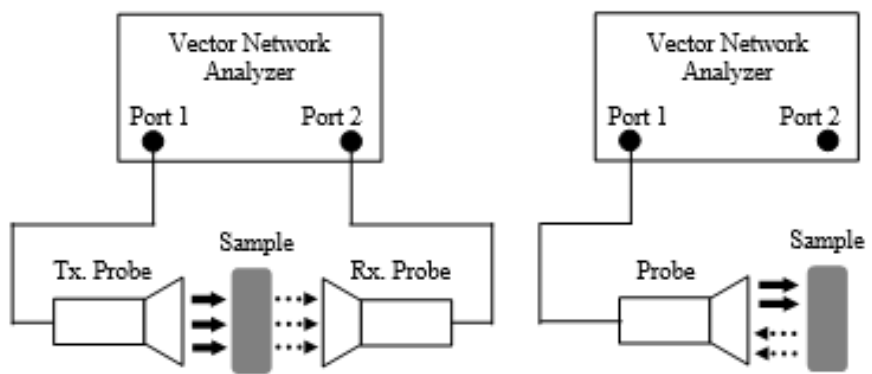

Fig. 2. Schematic of simple (left) transmission mode and (right) reflection mode for microwave passive measurement. The transmission mode requires two probes for transmission and reception, while reflection mode needs only single probe for transmission and reception of microwave sensing.

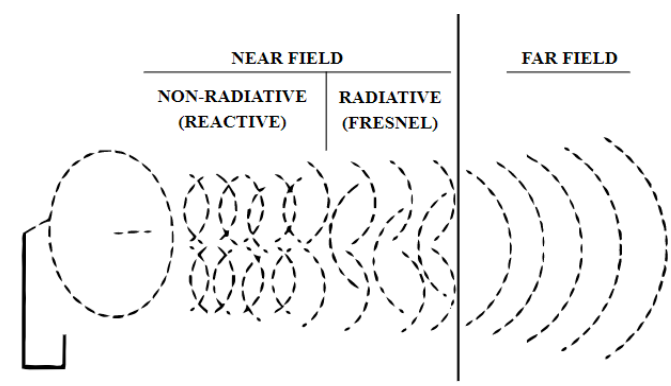

Fig. 3. Directions of transmitted and reflection waves related to nonraditative (reactive) and radiative (Fresnel), where the strength of electric and magnetic fields are difficult to be measured, while the distance of radiative is far enough to measure electric and magnetic fields [23].

\section{Concept and Assumption}

According to reflection mode measurement as seen in Fig. 4, a swept frequency band is fed by RF/Microwave source through a microwave sensor having a matched impedance of $50 \Omega$. Then, incident wave is further radiated to sample, and reflected wave is occurred, which may have a magnitude of reflected wave varied by sample properties, as well as phase or frequency [24-26]. The distance between microwave sensor and sample is referred to radiative range as discussed in the 
previous sub-section, where properties of sample undertested could be simply recognized by return loss $\left(S_{11}\right)$ or reflection coefficient $(\Gamma)$. The measurement system is recommended to be done in the shield room to avoid any interferences, which is affordable for high accuracy.

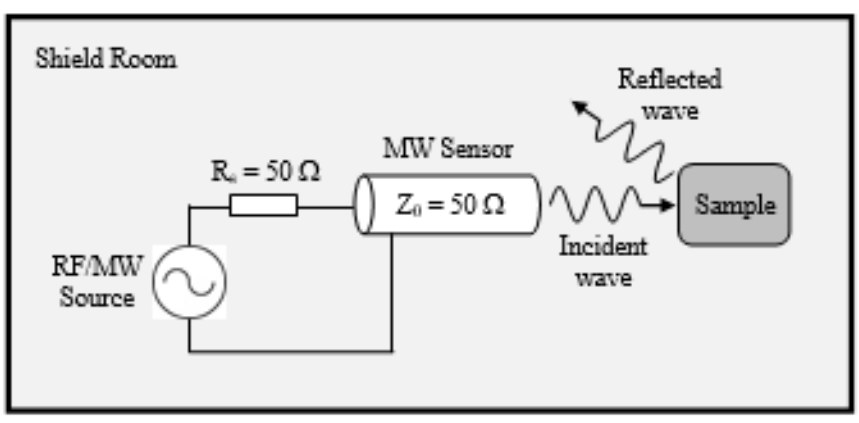

Fig. 4. The equivalent circuit model of reflection mode measurement system. RF/MW source produces a swept microwave band feeding to an input of microwave sensor having a matched impedance of $50-\Omega$. The incident and reflected waves occur at the surface of sample, which is affected by sample properties.

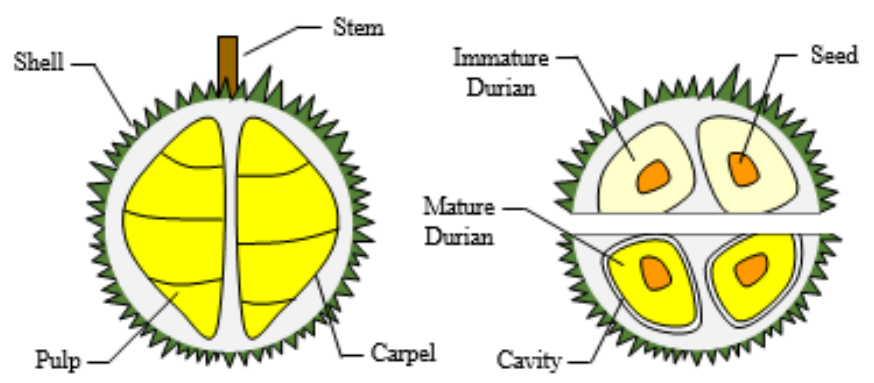

Fig. 5. Physical properties of durian; the cross sections of (left) side view and (right) top view, where a small cavity is occurred for mature durian. Therefore, maturity of durian can be investigated by cavity occurred in the carpel.

Fig. 5 shows physical properties of durian, where the cross sections of side view and top view are on the left and right of the figure. It is noted that a small cavity is occurred for mature durian. Therefore, maturity of durian can be investigated by the cavity occurred in the carpel. Unfortunately, durian fruit is a unique shape having spikes surrounded as seen in the figure. Hence, microwave sensor structure should be possible to reach a small surface between spikes to sense reflected wave. Due to its physical properties, it can be assumed that the magnitude of reflected wave obtained by immature durian should be more than the magnitude of reflected wave obtained by mature durian, as exhibited in Fig. 6. In the figure, incident, reflected and refracted wave behaviors are discussed comparing to immature and mature durian measurements. Homogeneous-like structure is considered for immature durian. On the other hands, heterogenous-like structure is considered for mature durian with a small cavity between inner shell (or ovary wall) and pulp. Considering immature and mature durian structures as seen in Fig. 6, it can be assumed that magnitude of reflected wave in case of immature durian is higher than at which of mature durian, due to a small cavity and water-content pulp. The waveguide structure is unexpectedly occurred for mature durian where dielectric constant of cavity is the lowest value compared to the others (inner shell and pulp), and watercontent pulp causes of wave scattering at the boundary of pulp surface. Thus, magnitude of reflected wave for mature durian measurement is very low.
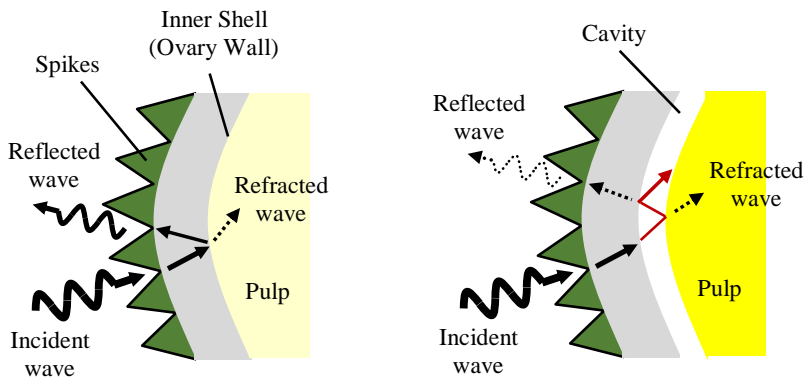

Fig. 6. Assumption of reflected wave behavior in the cases of (left) immature durian and (right) mature durian measurement. Immature durian is considered as homogeneous-like structure that may obtain higher magnitude of reflected wave compared to magnitude of reflected wave measured from mature durian, because of a small cavity occurred between inner shell and water-content pulp of mature durian.

\section{MICROWAVE SENSOR}

There are several measurement techniques and applications for non-destructive quality evaluation of agricultural products [27]. In our research, microwave sensor based planar structure having advantages of light weight, compactness, and ease of use was decided, where configuration of microwave sensor, so called "Pencil-like shaped microwave sensor" including a $50-\Omega$ quarter-wavelength feeder and radiator, as shown in Fig. 7 , which was developed from [28,29], where equivalent model is shown in Fig. 8.

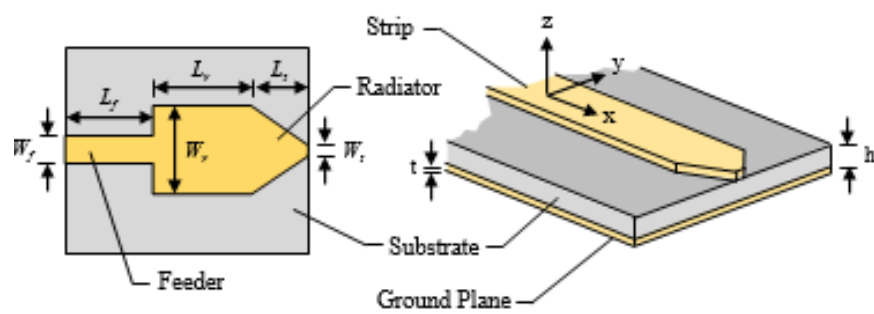

Fig. 7. Configuration of microwave sensor; (left) top view and (right) 3D side view, based planar structure, which is so called "Pencil-like shaped microwave sensor," including a $50-\Omega$ quarter-wavelength feeder, radiator designed based microstrip antenna, and a 7.5-to-50- $\Omega$ tapper strip. 


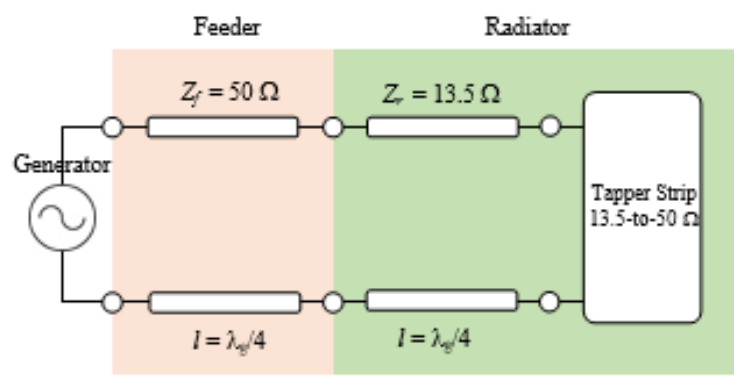

Fig. 8. The transmission line model of "Pencil-like shaped microwave sensor" based planar structure, including a $50-\Omega$ quarter-wavelength feeder, and $7.5-\Omega$ quarter-wavelength transmission line connected with 13.5 -to-50- $\Omega$ taper strip.

Regarding design equations [30-32], dimensions of our microwave sensor are as follows: a $50-\Omega$ quarter-wavelength feeder width $\left(W_{f}\right)$ and length $\left(L_{f}\right)$ are $3.08 \mathrm{~mm}$ and $12.10 \mathrm{~mm}$, and width $\left(W_{r}\right)$ and length $\left(L_{r}\right)$ of radiator are $17.70 \mathrm{~mm}$ and $12.10 \mathrm{~mm}$. Finally, tapper strip width $\left(W_{t}\right)$ and length $\left(L_{t}\right)$ were optimized to achieve matched impedance at $3.08 \mathrm{~mm}$ and 8.66 $\mathrm{mm}$. By using electromagnetic simulation, electical characteristics represented by return loss $\left(\mathrm{S}_{11}\right)$ and voltage standing wave ratio (VSWR) were calculated as $16.512 \mathrm{~dB}$ and 1.352 (or reflection coefficient, $|\Gamma|=0.149$ ), as shown in Fig. 9. In addition, radiation patterns on $\mathrm{X}$ (YZ-plane), Y (XZ-plane) and $\mathrm{Z}$ (XY-plane)-axises are exhibited in Fig. 10. The photograph of microwave sensor is shown in Fig. 11, where its dimension is $\mathrm{W} 30 \mathrm{~mm} \times \mathrm{L} 40 \mathrm{~mm}$.


Fig. 9. Electrical characteristics of microwave sensor represented by return loss $\left(\mathrm{S}_{11}\right)$ and voltage standing wave ratio (VSWR), where return loss is $16.512 \mathrm{~dB}$ and VSWR is 1.352 (or $|\Gamma|=0.149$ ), at a resonator frequency of $3.4767 \mathrm{GHz}$



(X-axis or YZ-plane)

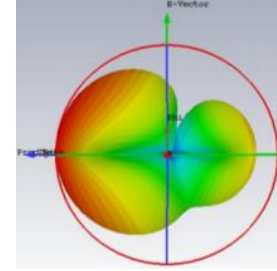

(Y-axis or XZ-plane)

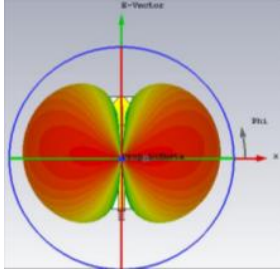

(Z-axis or XY-plane)
Fig. 10. Radiation patterns of microwave sensor at resonant frequency of 3.4 GHz on X (YZ-plane), Y (XZ-plane) and Z (XY-plane) axises. Noted that red means maximum electric intensity and blue means minimum electric intensity.
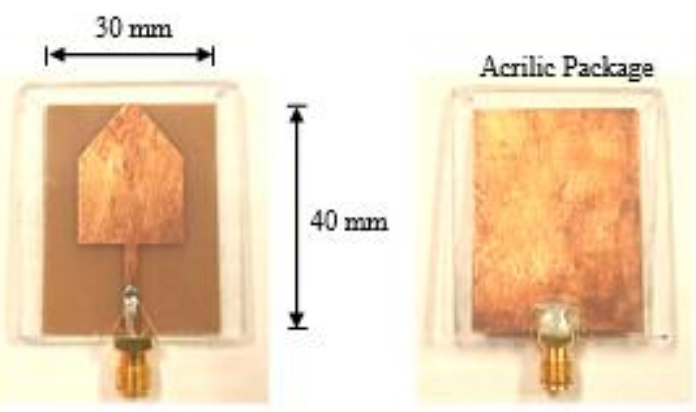

Fig. 11. Photograph of microwave sensor made of a FR4 laminate; (left) top view and (right) bottom view, having a SMA/F connector soldered at feeder. The microwave sensor dimension is $\mathrm{W} 30 \mathrm{~mm} \times \mathrm{L} 40 \mathrm{~mm}$.

\section{EXPERIMENT AND RESULTS}

The experimental setup of durian maturity measurement is shown in Fig. 12. Referring to equivalent circuit model in Figs. 4 and 8, network analyzer was used to be a generator to fed the swept frequency through coaxial cable to microwave sensor, and then to measure durian sample. Durian samples included 10-pieces for each immature, semi-mature, and mature durians, totally 30 pieces of durian sample. In particular, measurement environment was done in the shield house, to avoid any noises and interferences. Moreover, they were also measured for nine times for each sample to achieve measurement validity. The measurement results for immature, semi-mature, and mature durians are shown in Table 1.

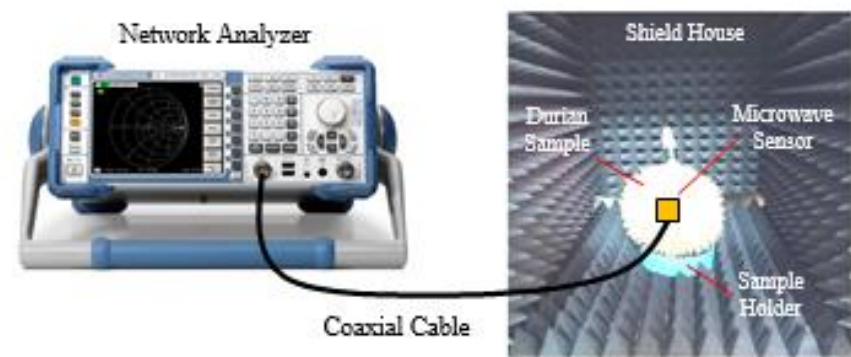

Fig. 12. Experimental setup of durian maturiy measurement, where vector analyzer was used to be a generator to feed swept microwave band through coaxial cable into microwave sensor, and then to measure durian sample. The experiment was done in the shield house to avoid noisese and interferences. 



FOR IMMATURE, SEMI-MATURE, AND MATURE DuRIans, with Nine TimES OF MEASUREMENT FOR EACH SAMPLE.

\begin{tabular}{|c|c|c|c|c|c|c|c|c|c|c|c|}
\hline \multicolumn{12}{|c|}{ Measurement Results of Return Loss $\left(\mathrm{S}_{11}\right)$ for Immature (Young) Durian Samples } \\
\hline \multicolumn{2}{|c|}{ Test No. } & $\# 1$ & \#2 & $\# 3$ & $\# 4$ & $\# 5$ & \#6 & \#7 & $\# 8$ & \#9 & $\bar{x}$ \\
\hline \multirow{11}{*}{ 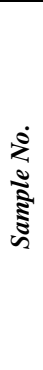 } & $\# 1$ & 6.1 & 5.0 & 6.3 & 6.2 & 4.6 & 4.8 & 5.2 & 6.4 & 5.2 & 5.53 \\
\hline & $\# 2$ & 4.4 & 4.3 & 5.0 & 5.4 & 5.8 & 6.2 & 5.8 & 6.1 & 4.6 & 5.28 \\
\hline & $\# 3$ & 5.6 & 4.9 & 5.7 & 4.8 & 4.5 & 4.7 & 5.9 & 4.2 & 4.5 & 4.97 \\
\hline & $\# 4$ & 4.9 & 4.8 & 5.2 & 4.8 & 4.4 & 6.2 & 5.8 & 5.5 & 6.1 & 5.30 \\
\hline & $\# 5$ & 5.6 & 5.7 & 5.5 & 5.4 & 4.8 & 4.9 & 4.4 & 4.4 & 4.6 & 5.03 \\
\hline & $\# 6$ & 4.7 & 4.6 & 4.5 & 4.2 & 4.9 & 5.1 & 5.3 & 4.4 & 4.5 & 4.68 \\
\hline & $\# 7$ & 5.7 & 5.6 & 5.6 & 5.4 & 4.6 & 5.2 & 5.4 & 4.6 & 4.4 & 5.16 \\
\hline & $\# 8$ & 5.2 & 5.8 & 5.5 & 5.3 & 5.1 & 4.5 & 4.6 & 4.3 & 4.4 & 4.96 \\
\hline & $\# 9$ & 4.8 & 5.0 & 5.6 & 5.4 & 6.2 & 5.9 & 5.9 & 5.8 & 5.0 & 5.51 \\
\hline & $\# 10$ & 5.2 & 5.5 & 4.9 & 4.8 & 4.5 & 4.9 & 5.2 & 5.5 & 5.9 & 5.16 \\
\hline & \multicolumn{11}{|c|}{ Min. $=5.03 \mathrm{~dB} /$ Max. $=5.53 \mathrm{~dB} / \mathrm{Av} .=5.158 \mathrm{~dB}$} \\
\hline \multicolumn{12}{|c|}{ Measurement Results of Return Loss $\left(S_{11}\right)$ for Semi-Mature Durian Samples } \\
\hline \multicolumn{2}{|c|}{ Test No. } & $\# 1$ & \#2 & \#3 & \#4 & \#5 & \#6 & \#7 & $\# 8$ & \#9 & $\bar{x}$ \\
\hline \multirow{11}{*}{ 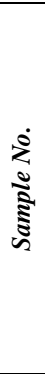 } & \#1 & 6.8 & 7.2 & 7.5 & 8.2 & 8.1 & 7.8 & 8.5 & 9.1 & 10.3 & 8.17 \\
\hline & \#2 & 8.9 & 9.4 & 10.2 & 10.6 & 11.2 & 10.8 & 11.4 & 11.6 & 12.0 & 10.68 \\
\hline & \#3 & 9.8 & 10.2 & 10.7 & 11.1 & 11.3 & 11.3 & 11.5 & 1.4 & 11.8 & 11.01 \\
\hline & \#4 & 6.8 & 7.2 & 7.3 & 7.0 & 7.9 & 8.5 & 9.2 & 10.6 & 10.5 & 8.33 \\
\hline & $\# 5$ & 7.6 & 7.0 & 7.4 & 7.5 & 7.0 & 7.4 & 7.4 & 7.5 & 7.6 & 7.38 \\
\hline & \#6 & 8.8 & 8.7 & 8.9 & 9.1 & 9.4 & 9.8 & 10.2 & 10.5 & 11.0 & 9.6 \\
\hline & $\# 7$ & 7.9 & 7.7 & 8.4 & 8.8 & 9.5 & 10.2 & 10.6 & 10.9 & 11.4 & 9.49 \\
\hline & \#8 & $\begin{array}{l}9.8 \\
\end{array}$ & 9.7 & 10.4 & 10.9 & 11.3 & 11.6 & 11.8 & 11.9 & 12.0 & 11.03 \\
\hline & \#9 & 8.9 & 8.7 & 8.5 & 9.2 & 9.6 & 10.2 & 10.6 & 11.3 & 11.6 & 9.84 \\
\hline & \#10 & $\begin{array}{l}7.8 \\
\end{array}$ & 7.7 & 7.3 & 7.0 & 7.9 & 6.5 & 7.6 & 7.6 & 6.5 & 7.32 \\
\hline & Min. & $=7.32$ & $\mathrm{iB} / \mathrm{M}$ & $\mathrm{x}=11$ & $3 \mathrm{~dB} /$ & Av. $=9$ & $285 \mathrm{~dB}$ & & & & \\
\hline \multicolumn{12}{|c|}{ Measurement Results of Return Loss $\left(\mathrm{S}_{11}\right)$ for Mature Durian Samples } \\
\hline \multicolumn{2}{|c|}{ Test No. } & $\# 1$ & $\# 2$ & $\# 3$ & $\# 4$ & $\# 5$ & $\# 6$ & $\# 7$ & $\# 8$ & $\# 9$ & $\bar{x}$ \\
\hline \multirow{11}{*}{ 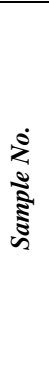 } & $\# 1$ & 12.9 & 13.2 & 13.5 & 13.7 & 14.7 & 15.2 & 15.3 & 15.7 & 16.3 & 14.5 \\
\hline & $\# 2$ & 13.8 & 14.2 & 14.5 & 14.7 & 15.2 & 15.6 & 16.2 & 16.7 & 16.9 & 15.31 \\
\hline & $\# 3$ & 15.4 & 15.3 & 14.9 & 14.5 & 14.7 & 15.2 & 15.8 & 16.5 & 17.0 & 15.47 \\
\hline & $\# 4$ & 18.9 & 19.0 & 18.8 & 18.5 & 18.3 & 17.9 & 17.5 & 16.8 & 17.5 & 18.13 \\
\hline & $\# 5$ & 16.5 & 16.3 & 16.5 & 16.2 & 15.8 & 15.9 & 16.2 & 15.7 & 14.0 & 15.9 \\
\hline & $\# 6$ & 12.4 & 12.6 & 13.0 & 13.5 & 14.0 & 14.4 & 15.3 & 15.9 & 16.4 & 14.17 \\
\hline & $\# 7$ & 13.2 & 13.5 & 13.8 & 14.2 & 15.2 & 15.5 & 16.2 & 16.7 & 17.3 & 15.07 \\
\hline & $\# 8$ & 12.6 & 12.9 & 13.5 & 14.2 & 14.6 & 15.2 & 15.5 & 15.8 & 15.9 & 14.47 \\
\hline & $\# 9$ & 13.5 & 13.6 & 13.9 & 14.5 & 14.5 & 14.9 & 17.3 & 17.7 & 18.0 & 15.32 \\
\hline & $\# 10$ & 18.6 & 18.5 & 17.7 & 16.3 & 16.9 & 17.6 & 18.4 & 18.9 & 19.0 & 17.99 \\
\hline & & & & & & & & & & & \\
\hline
\end{tabular}

The measurement results in Table 1 show different values of return loss for the cases of immature, semi-mature, and mature durians measurement. The measured return losses were in the range of 5.03-5.53 dB, 7.32-11.03, and 14.5-18.13 dB for immature, semi-mature, and mature durians, respectively. So those measured return loss values are converted to reflection coefficient; $|\Gamma|=0.53-0.56$ for immature durian, $|\Gamma|=0.28$ 0.43 for semi-mature durian, and $|\Gamma|=0.12-0.19$ for mature durian. It can be written as seen at the below equations. Furthermore, prediction accuracy of other samples measurements were achieved as $91.55-99 \%$ by using reference values as shown in Fig. 13.

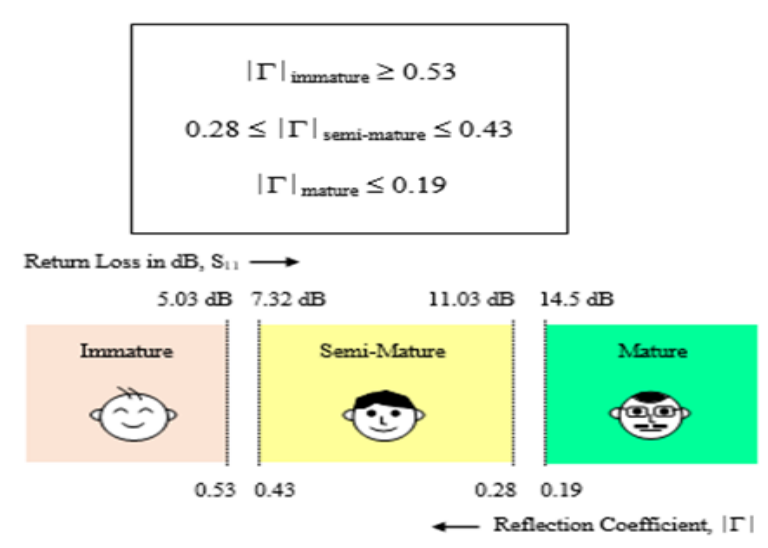

Fig. 13. Stage diagram of durian maturity classification by return loss $\left(S_{11}\right)$ and reflection coefficient $(|\Gamma|)$; where immature as $S_{11} \leq 5.03 \mathrm{~dB}$ or $|\Gamma| \geq$ 0.53 , semi-mature as $7.32 \mathrm{~dB} \leq \mathrm{S}_{11} \leq 11.03 \mathrm{~dB}$ or $0.28 \leq|\Gamma| \leq 0.43$, and mature as $\mathrm{S} 11 \geq 14.5 \mathrm{~dB}$ or $|\Gamma| \leq 0.19$. 
It was noted that our measurement system achieved higher prediction accuracy comparing to impedance measurement at $83.3 \%$ [5] and microwave free space measurement at 90\% [9]. However, it was also not less than other works as vibration and ultrasonic sensing method at 95\% [6], RF and microwave band measurement at $92.7 \%$ [8], and absorbance measurement by visible spectroscopy at $94.7 \%$ [10].

\section{CONCLUSION}

In this paper, non-destructive durian maturity classification has been reported based near-field reflection mode measurement by using a $3.4-\mathrm{GHz}$ pencil-like shaped microwave sensor which made of a FR4 laminate. In our experiments, immature, semi-mature, and mature durians can be classified by means of return loss $\left(S_{11}\right)$ or reflection coefficient $(|\Gamma|)$; where immature as $\mathrm{S}_{11} \leq 5.03 \mathrm{~dB}$ or $|\Gamma| \geq 0.53$, semi-mature as $7.32 \mathrm{~dB} \leq \mathrm{S}_{11} \leq 11.03 \mathrm{~dB}$ or $0.28 \leq|\Gamma| \leq 0.43$, and mature as $\mathrm{S}_{11} \geq 14.5 \mathrm{~dB}$ or $|\Gamma| \leq 0.19$, where measurement accuracy of our proposed system achieved as $91.55-99 \%$.

\section{ACKNOWLEDGMENT}

The authors would like to thank for financial support by National Research Council of Thailand (NRCT), research grant no. \#256107A1650009, and special thank for experiments by Mr.Chatrawut Srihanon, Mr.Worawit Praneet, and Ms.Panchanok Kimsang, who are recently bachelor students from Division of Electronic \& Automation System Engineering Education, Department of Industrial Education, Faculty of Technical Education, Rajamangala University of Technology Thanyaburi.

\section{REFERENCES}

[1] www.impexp.oae.go.th [Office of Agricultural Econimics, Ministry of Agriculture and Cooperatives, Thailand]

[2] National Bureau of Agricutural Commodity and Food Standards, "Thai agricutural standards: TAS 3-2013," Royal Thai Government Gazette, vol. 131, no. 31d, 2014

[3] S.O. Nelson, L.H. Soderholm, and F.D. Yung, "Determining the dielectric propoerties of grain," Agri. Eng., vol. 34, no. 9, pp. 608-610, 1953

[4] S.O. Nelson, "Measurement and applications of dielectric properties of agricultural products," IEEE Trans. Instru. Meas., vol 41, no. 1, pp. 116122, 1992

[5] P. Kuson and A. Terdwongworakul, "Minimally-destructive evaluation of durian maturity based on electrical impedance measurement," J. Food Eng., vol. 116, no. 1, 2013

[6] W. Kongrattanaprasert, S. Arunrungrasmi, B. Pungsiri, K. Chamnongthai, and M. Okuda, "Nondestructive maturity determination of durian by force vibration and ultrasonic," Intl. J. Uncertainty, Fuzziness and Knowledge-Based Systems, vol. 9, no. 6, pp. 703-719, 2001.

[7] A. Terdwongworakul and N. Neamsang, "Non-destructive maturity measurement of 'Montong' durian using stem strength and resonant frequency,” KKU Eng. J., vol. 33, no. 5, pp. 555-563, 2006.

[8] T. Rutpralom, P. Kumhom, and K. Chamnongthai, "Nondestructive maturity determination of durian by using microwave moisture sensing," IEEE Intl. Conf. Industrial and Tech., pp. 155-158, 2002.

[9] T. Rutpralom, K. Chamnongthai, P. Kumhom, and M. Krairiksh, "Nondestructive durian maturity determination by using microwave free space measurement," IEEE Intl. Symp. Circuits and Syst., pp. 13511354,2006

[10] P. Leekul, S. Chivaprecha, Ch. Phongcharoenpanich, and M. Krairiksh, "Recian k-factors-based sensor for fruit classifiction by maturity stage," IEEE Sensors J., vol. 16, no. 17, pp. 6659-6565, June 2016P. Timkhun and A. Terdwongworakul, "Non-destructive classification of durian maturity of 'Monthong' cultivar by means of visible spectroscopy of the spine,” J. Food. Eng., vol. 112, no. 4, pp. 263-267, 2012

[11] P. Sawetmethikul, Ch. Pansong, and N. Chaiwino, "Non-destructive inspection of reinforced concrete using high frequency probe," Proc. EENET 2016, 2016

[12] P. Sawetmethikul, U. Jantaratapo, and S. Wangkhuntod, "Classification of standard paddy moisture content using a low-profile microwave probe with reflection mode measurement," Proc. ECTI-CARD 2018, pp. 127 130, 2018.

[13] S. Theerawisitpong, T. Suzuki, T. Negishi, and Y. Watanabe, "Nearfield transmission imaging by $60 \mathrm{GHz}$ band waveguide-type microscopic aperture probe," IEICE Trans. Commun., vol. E90-B, no. 9, pp. 2387-2393, 2007.

[14] S. Tantong, B.C.-Raga, Ph. Kirawanich, and N. Islam, "Near-field microwave imaging techniques for object detection and shape reconstruction," Proc. IEEE Region 5 Tech. Conf., pp. 299-302, 2007.

[15] P.F. Medina, A. Lucibello, G. Gramse, E. Brinciotti, M. Kasper, A.O Oladipo, R. Feger, A. Stelzer, H. Tanbakuchi, R. Stancliff, E. Proietti, R. Marcelli, and F. Kienberger, "Transmission and reflection mode scanning microwave microscopy (SMM): experiments, calibration, and simulation," Proc. 45 ${ }^{\text {th }}$ European Microw. Conf., pp. 654-657, 2015.

[16] C.A. Balanis, Antenna Theory: Analysis and Design, 3rd ed., NJ : John Wiley \& Sons, Inc., 2005

[17] keysight.com "Near-field vs Far-field" 2020. [Online]. Retrieved from: https://www.keysight.com/upload/cmc_upload/All/NSI-near-far.pdf

[18] K.J. Bois, A.D. Benally, and R. Zoughi, "Microwave near-field reflection property analysis for concrete for material content determination," IEEE Trans. Instru. \& Meas., vol. 49, no. 1, pp. 49-55, 2000

[19] M. Maazi, O. Benzaim, D. Glay, and T. Lasri, "Detection an characterization of buried macroscopic cracks inside dielectric materials by microwave techniques and artificial neural networks," IEEE Trans. Instru. Meas., vol. 57, no. 12, pp. 2819-2826, 2008.

[20] I. Russo and W. Menzel, "4-8 GHz near-field probe for scanning of apertures and multimode waveguides," IEEE Microw. \& Wirel. Compon. Lett., vol. 21, no. 12, 2011

[21] M.R. Ramzi, M. Abou-Khousa, and Im Prayudi, "Near-field microwave imaging using open-ended circular waveguide probes," IEEE Sensors J., vol. 17, no, 8, pp. 2359-2366, 2017.

[22] J.M. Felicio, J.M. Bioucas-Dias, J.R. Costa, C.A. Fernandes, "Antenna design and near-field characterization for medical microwave imaging applications," IEEE Trans. Ant. \& Propaga., vol. 67, no. 7, pp. 48114824, 2019

[23] https://en.wikipedia.org/wiki/Near_and_far_field

[24] J.C.E. Sten and A. Hujanen, "Aspects on the phase delay and phase velocity in the electromagnetic near-field," Prog. Electromag. Res., vol 56, pp. 67-80, 2006

[25] R. Joffe, E.O. Kamenetskii, and R. Shavit, "Novel microwave near-field sensors for material characterization, biology, and nano technology," J. Appl. Phys., vol 112, no. 063912 (2013), 2012.

[26] M.S. Safa, V. Neyyeri, A. Ghadimi, M. Soleimani, and O.M. Ramahi, "A pixelated microwave near-field sensor for precies characterization of dielectric materials," Scientific Reports, vol. 9, no. 13310, 2019.

[27] S.N. Jha, K. Narsaiah, A.L. Basediya, R. Sharma, P. Jaiswal, R. Kumar, and R. Bhardwaj, "Measurement techniques and application of electrica properties for nondestructive quality evaluation of foods - a review," J. Food Sci \& Tech., vol 48, no. 4, pp. 387-411, 2011. 
[28] M.U. Memon and S. Lim, "Review of electromagnetic-based crack sensors for metallic materials (recent research and future perspectives)," J. Metal, vol. 6, no. 172, 2016.

[29] J. Kerouedan, P. Queffelec, P. Talbot, C. Quendo, S.D. Blasi, and A.L. Brun, "Detection of micro-cracks on metal surfaces using near-field micrwoave resonators," J. Meas. Sci. \& Tech., vol. 19, no. 10, 2008.

[30] D.M. Pozar, Microwave Engineering, 4th ed., NJ : John Wiley \& Sons, Inc., 2012.
[31] R. Garg, I. Bahl, and M. Bozzi, Microstrip Lines and Slotlines, 3rd ed. Artech House, 2013.

[32] J.S. Hong and M. Lancaster, Microstrip Filters for RF/Microwave Applications (Wiley Serices in Microwave and Optical Engineering 126), 2001. 